\title{
Notes
}

\section{Reversible and Site-Specific Reduction of the Ligand Sides in a Molecular Rectangle with up to Eight Electrons}

\author{
Heiko Hartmann, ${ }^{\dagger}$ Sascha Berger, ${ }^{\dagger}$ Rainer Winter, ${ }^{\dagger}$ \\ Jan Fiedler,,$\stackrel{\star}{*}$ and Wolfgang Kaim ${ }^{*}, \dagger$
}

Institut für Anorganische Chemie, Universität Stuttgart, Pfaffenwaldring 55, D-70550 Stuttgart, Germany, and J. Heyrovsky Institute of Physical Chemistry, Academy of Sciences of the Czech Republic, Dolejškova 3, CZ-18223 Prague, Czech Republic

Received February 1, 2000

\section{Introduction}

Molecular squares and rectangles with metal corners and ligand sides have become increasingly available as structurally characterized "supramolecular" entities. ${ }^{1,2}$ Apart from the structural fascination, the question of molecular recognition, and the development of synthetic strategies, another attractive aspect of these kinds of structured assemblies is their potential function in photo- or electrochemistry ${ }^{2,3}$ and molecular electronics. ${ }^{4}$ Whereas the antenna function of supramolecular aggregates has been studied ${ }^{2,3}$ and magnetically interacting systems were reported recently, ${ }^{5}$ there is a scarcity of electron-transfer studies of molecular squares and rectangles. ${ }^{1,2}$

Although both $4,4^{\prime}$-bipyridine (bp) ${ }^{6}$ and bis-chelating $2,2^{\prime}$ bipyrimidine (bpym $)^{7}$ are reducible ligands, especially when symmetrically coordinated to metals, the recently reported and structurally characterized tetrarhenium(I) molecular rectangle $\left[(\mathrm{bp})_{2}(\mathrm{bpym})_{2}(\mathrm{OC})_{12} \mathrm{Re}_{4}\right]^{4+}\left(\mathbf{1}^{4+}\right)$ was described to yield "only irreversible waves for both the reduction and oxidation reactions" in acetonitrile. ${ }^{8}$ In consideration of our previous experience with successive reversible multielectron uptake by metal complexes with several different unsaturated heterocyclic ligands, ${ }^{9}$ we have investigated $(\mathbf{1})\left(\mathrm{CF}_{3} \mathrm{SO}_{3}\right)_{4}$ via cyclic volta-

\section{$\dagger$ Universität Stuttgart.}

$\doteqdot$ Academy of Sciences of the Czech Republic.

(1) (a) Stang, P. J.; Olenyuk, B. Acc. Chem. Res. 1997, 30, 502. (b) Fujita, M.; Yazaki, J.; Ogura, K. J. Am. Chem. Soc. 1990, 112, 5645.

(2) (a) Slone, R. V.; Benkstein, K. D.; Bélanger, S.; Hupp, J. T.; Guzei, I. A.; Rheingold, A. L. Coord. Chem. Rev. 1998, 171, 221. (b) Slone, R. V.; Hupp, J. T.; Stern, C. L.; Albrecht-Schmitt, T. E. Inorg. Chem. 1996, 35, 4096. (c) Sun, S.-S.; Lees, A. J. Inorg. Chem. 1999, 38, 4181. (d) Rajendran, T.; Manimaran, B.; Lee, F.-Y.; Lee, G.-H.; Peng, S.-M.; Wang, C. M.; Lu, K.-L. Inorg. Chem. 2000, 39, 2016.

(3) Lehn, J.-M. Supramolecular Chemistry: Concepts and Perspectives; VCH: Weinheim, Germany, 1995.

(4) Lent, C. S. Science 2000, 288, 1597.

(5) Campo-Fernandez, C. S.; Clérac, R.; Dunbar, K. R. Angew. Chem. 1999, 111, 3685; Angew. Chem., Int. Ed. Engl. 1999, 38, 3477.

(6) Bruns, W.; Kaim, W.; Waldhör, E.; Krejcik, M. Inorg. Chem. 1995, $34,4,663$.

(7) (a) Kaim, W.; Kohlmann, S. Inorg. Chem. 1987, 26, 68. (b) Kaim, W.; Bruns, W.; Kohlmann, S.; Krejcik, M. Inorg. Chim. Acta 1995, $229,143$.

(8) Benkstein, K. D.; Hupp, J. T.; Stern, C. L. J. Am. Chem. Soc. 1998, 120, 12982.

(9) (a) Fees, J.; Kaim, W.; Moscherosch, M.; Matheis, W.; Klima, J.; Krejcik, M.; Zalis, S. Inorg. Chem. 1993, 32, 166. (b) Berger, S.; Klein, A.; Kaim, W.; Fiedler, J. Inorg. Chem. 1998, 37, 5664.

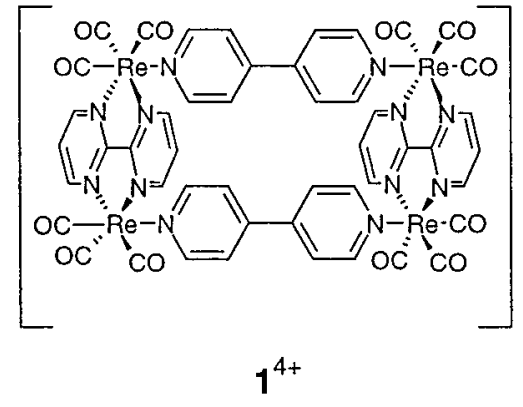

mmetry and UV/vis/IR spectroelectrochemistry, using an optically transparent thin-layer electrolytic (OTTLE) system. ${ }^{10}$

\section{Results and Discussion}

The compound $(\mathbf{1})\left(\mathrm{CF}_{3} \mathrm{SO}_{3}\right)_{4}$ was obtained as reported ${ }^{8}$ and was subjected to cyclic voltammetry in DMF/0.1 $\mathrm{M} \mathrm{Bu}_{4} \mathrm{NPF}_{6}$ and $\mathrm{CH}_{3} \mathrm{CN} / 0.1 \mathrm{M} \mathrm{Bu}_{4} \mathrm{NPF}_{6}$. Dry $N, N$-dimethylformamide in particular is a superior solvent for studying multiple electrontransfer processes in the negative potential region..$^{9 \mathrm{a}}$ The cyclic voltammogram in DMF (Figure 1) exhibits four sets of twoelectron waves, of which the two at most negative potentials show a clear splitting into two one-electron processes. A Baranski analysis ${ }^{11}$ of the first wave clearly documents the twoelectron character, and a graphical simulation ${ }^{12}$ of the cyclic voltammogram (Figure 1) yields the data summarized in Table 1.

The cyclic voltammogram of $(\mathbf{1})\left(\mathrm{CF}_{3} \mathrm{SO}_{3}\right)_{4}$ in $\mathrm{CH}_{3} \mathrm{CN} / 0.1 \mathrm{M}$ $\mathrm{Bu}_{4} \mathrm{NPF}_{6}$ shows features at similar potentials as in DMF; however, even the first reduction process is not ideally reversible but exhibits an anodically shifted $(\Delta E=0.27 \mathrm{~V})$ additional reoxidation peak. Substitutional lability in the presence of the potential ligand acetonitrile $\mathrm{e}^{\mathrm{bb}, 14}$ and adsorption effects at more negative potentials are probably responsible for this nonreversible behavior ${ }^{8}$ in $\mathrm{CH}_{3} \mathrm{CN}$.

Returning to DMF, the mere registration of electrode potentials does not reveal the sites of the individual electron uptake processes, although previous experience ${ }^{6,7}$ would suggest more facile reduction of the bpym ligands. In comparison to bp, bpym contains two more electronegative nitrogen atoms instead of two $\mathrm{CH}$ groups. In addition, the metal coordination to four $\mathrm{N}$ centers of bpym is likely to shift the reduction potential to less negative values via stabilization of the $\pi^{*} \mathrm{MO} .^{7 \mathrm{a}}$ Unfortunately, EPR spectroscopy is not a useful means of localizing the site of electron addition to $\mathbf{1}^{4+}$ because of the severe broadening occurring for large (i.e. slowly tumbling) radical species containing the dominating ${ }^{185,187} \mathrm{Re}$ isotopes ${ }^{9 b, 13,14}$ and the two-electron character of the first two waves.

We therefore used OTTLE spectroelectrochemistry ${ }^{10}$ in the UV/vis region. The $\mathrm{bp}^{-15}$ and bpym ${ }^{--}$chromophors ${ }^{16}$ differ

(10) Krejcik, M.; Danek, M.; Hartl, F. J. Electroanal. Chem., Interfacial Electrochem. 1991, 317, 179.

(11) Baranski, A. S.; Fawcett, W. R.; Gilbert, C. M. Anal. Chem. 1985 $57,166$.

(12) Program DigiSim 2.1; Bioanalytical Systems, West Lafayette, IN

(13) Kaim, W.; Kohlmann, S. Inorg. Chem. 1990, 29, 2909.

(14) Klein, A.; Vogler, C.; Kaim, W. Organometallics 1996, 15, 236. 

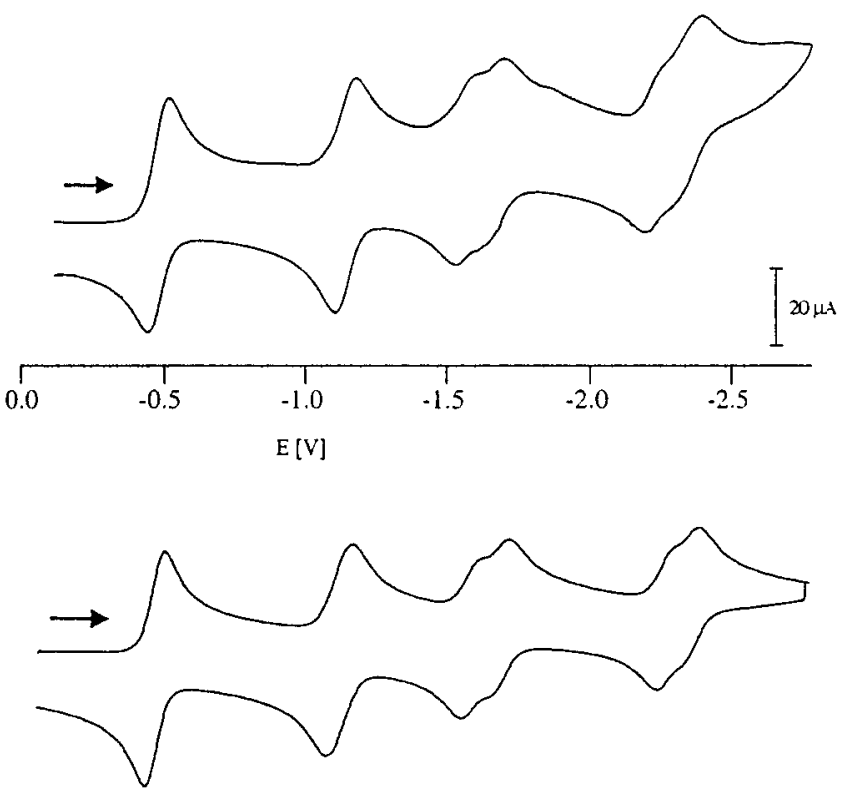

Figure 1. Cyclic voltammogram of $(\mathbf{1})\left(\mathrm{CF}_{3} \mathrm{SO}_{3}\right)_{4}$ in $\mathrm{DMF} / 0.1 \mathrm{M} \mathrm{Bu}_{4^{-}}$ $\mathrm{NPF}_{6}$ at $200 \mathrm{mV} / \mathrm{s}$ scan rate: (top) potentials $E$ vs $\left(\mathrm{C}_{5} \mathrm{H}_{5}\right)_{2} \mathrm{Fe}^{+/ 0}$; (bottom) graphic simulation (DigiSim 2.1) using the data from Table 1.

sufficiently, which provides a means for distinguishing the sites of electron uptake. The long-wavelength features are most indicative: while $\mathrm{bp}^{--}$exhibits a fairly intense structured band around $600 \mathrm{~nm},{ }^{15}$ familiar from the coloring of reduced "methylviologen", the radical anion bpym ${ }^{--}$and the dianion bpym $^{2-}$ display much weaker, forbidden, and usually vibrationally structured $\pi \rightarrow \pi^{*}\left(\pi_{7} \rightarrow \pi_{8}\right)$ transitions with maxima beyond $750 \mathrm{~nm}$ in the near-infrared region. ${ }^{16}$

Figure 2 illustrates the UV/vis spectroelectrochemical response of $(\mathbf{1})\left(\mathrm{CF}_{3} \mathrm{SO}_{3}\right)_{4}$. The first two-electron-reduction process causes the emergence of a weak $\left(\epsilon<10^{3} \mathrm{M}^{-1} \mathrm{~cm}^{-1}\right)$ broadband system between 600 and $1300 \mathrm{~nm}$ which changes only slightly after two more electrons have been added. This behavior indicates simultaneous reduction of the bpym ligand "sides" of the rectangle $\mathbf{1}^{4+}$ (Scheme 1).

Following the now stepwise addition of two more electrons, an intense, structured band system emerges in the visible region (Figure 2) with the main maximum at $585 \mathrm{~nm}$ and other features at 630,745 , and $850 \mathrm{~nm}$. This pattern is rather similar to that of bp ${ }^{-}$in MTHF $(585,650,845,970 \mathrm{~nm}) .{ }^{15}$ On acquisition of the seventh electron this band begins to decrease (Figure 2) due to the further reduction of $\mathrm{bp}^{--}$to $\mathrm{bp}^{2-}$; spectroelectrochemistry of the last step was not possible due to slow but detectable degradation of the system.

The presence of the $f a c-\operatorname{Re}(\mathrm{CO})_{3}$ corners in the molecular rectangle $\mathbf{1}^{4+}$ provides an additional opportunity to monitor the electron-transfer processes by spectroelectrochemistry, this time in the carbonyl stretching region of the IR (Figure 3, Table 1).
Scheme 1

$$
\begin{aligned}
& {\left[(\mathrm{bp})_{2}(\mathrm{bpym})_{2}(\mathrm{OC})_{12} \operatorname{Re}_{4}{ }_{4}^{\mathrm{I}}\right]^{4+}} \\
& -2 \mathrm{e}^{-} \uparrow \downarrow+2 \mathrm{e}^{-} \\
& {\left[(\mathrm{bp})_{2}\left(\mathrm{bpym}^{\circ}\right)_{2}(\mathrm{OC})_{12} \operatorname{Re}_{4}^{\mathrm{I}}\right]^{2+}} \\
& -2 \mathrm{e}^{-\uparrow \downarrow}+2 \mathrm{e}^{-} \\
& {\left[(\mathrm{bp})_{2}\left(\mathrm{bpym}^{2-}\right)_{2}(\mathrm{OC})_{12} \mathrm{Re}_{4}^{\mathrm{l}}\right]^{\mathrm{o}}} \\
& -e^{-\uparrow \downarrow}+e^{-} \\
& {\left[\left(\mathrm{bp}{ }^{\circ}\right)(\mathrm{bp})\left(\mathrm{bpym}^{2-}\right)_{2}(\mathrm{OC})_{12} \operatorname{Re}_{4}^{\mathrm{I}}\right]^{\top}} \\
& -e^{-\uparrow \downarrow}+e^{-} \\
& {\left[\left(\mathrm{bp}^{\circ}\right)_{2}\left(\mathrm{bpym}^{2-}\right)_{2}(\mathrm{OC})_{12} \operatorname{Re}_{4}^{\mathrm{I}}\right]^{2-}} \\
& -e^{-} \uparrow \downarrow+e^{-} \\
& {\left[\left(\mathrm{bp}^{2-}\right)\left(\mathrm{bp}{ }^{\circ}\right)\left(\mathrm{bpym}^{2-}\right)_{2}(\mathrm{OC})_{12} \mathrm{Re}_{4}^{\mathrm{I}}\right]^{3-}} \\
& -e^{-} \uparrow \downarrow+e^{-} \\
& {\left[\left(\mathrm{bp}^{2-}\right)_{2}\left(\mathrm{bpym}^{2-}\right)_{2}(\mathrm{OC})_{12} \mathrm{Re}_{4}^{\mathrm{I}}\right]^{4-}}
\end{aligned}
$$

The typical ${ }^{9 a, 13,14,17}$ pattern of one narrow band $\left(\mathrm{A}_{1}\right)$ and one broad feature ( $\mathrm{E}$ in approximate $C_{3 v}$ symmetry, otherwise $\mathrm{A}^{\prime}+$ $\left.A^{\prime \prime}\right)$ experiences the expected ${ }^{7,17}$ low-energy shift upon reduction. Whereas the first two two-electron waves cause significant shifts in the range between 15 and $40 \mathrm{~cm}^{-1}$ for each 2e step, the following electron uptake results in distinctly smaller shifts of only a few wavenumbers (Table 1). Apparently, but not surprisingly, the reduction of the bidentate bpym ligands affects the $(\mathrm{Re}-) \mathrm{C}=\mathrm{O}$ bond orders and thus the $\mathrm{CO}$ stretching frequencies much more than electron uptake by the bismonodentate bp ligands. Similar observations were made previously for the complexes $\left[(\mathrm{MQ})(\mathrm{N} \wedge \mathrm{N})(\mathrm{OC})_{3} \mathrm{Re}\right]^{n}\left(\mathrm{MQ}^{+}=\right.$ 1-methyl-4,4'-bipyridinium, $\mathrm{N} \wedge \mathrm{N}=\alpha$-diimine chelate ligand, $n=2+,+, 0,-) .9 \mathrm{~b}$ The larger shifts of the CO stretching bands during the last reduction step can be ascribed to the formation of a quinoidal ring structure of the doubly reduced bp ligand and hence increased donor ability of the $\mathrm{N}$ atoms. The spectra in the last set are partially obscured, and the isosbestic point is lost.

From the spectroelectrochemical information we suggest a sequence of site-specific electron transfer processes to the molecular rectangle $\mathbf{1}^{4+}$ as shown in Scheme 1.

An interesting observation is the splitting of the third and

Table 1. Data for $\mathbf{1}^{n}$ from Cyclic Voltammetry ${ }^{a}$ and UV/vis/near-IR and IR Spectroelectrochemistry ${ }^{b, c}$

\begin{tabular}{llll}
\hline$n$ & $E_{1 / 2}(\text { red })^{a}$ & \multicolumn{1}{c}{$\lambda_{\max }(\epsilon)^{b}$} & $v_{\mathrm{CO}}{ }^{b}$ \\
\hline $4+$ & $-0.48^{d}$ & $445(4700), 316(27400)$ & 2041,1951 \\
$2+$ & $-1.13^{d}$ & $1100 \mathrm{sh}, 910(5550), 425 \mathrm{sh}, 304(32 \mathrm{700})$ & 2025,1931 \\
0 & -1.59 & $1300 \mathrm{sh}, 1070(900), 890(800), 335 \mathrm{sh}, 295(30200)$ & 2009,1890 \\
$1-$ & -1.70 & $1070(900), 850(1900), 750 \mathrm{sh}, 634(8600), 585(8800), 411(17500), 340 \mathrm{sh}, 297(24600)$ & 2009,1889 \\
$2-$ & -2.27 & $1070(900), 852(2300), 750 \mathrm{sh}, 630(13200), 585(15200), 410(30900), 299(24400)$ & 2009,1888 \\
$3-$ & -2.37 & $1070(900), 850(2300), 747(4200), 645 \mathrm{sh}, 587(14000), 405(39000), 295(25000)$ & $e$
\end{tabular}

${ }^{a}$ In DMF/0.1 M Bu $\mathrm{NPF}_{6}$ at $200 \mathrm{mV} / \mathrm{s}$ scan rate. Potentials in $\mathrm{V}$ vs $\left(\mathrm{C}_{5} \mathrm{H}_{5}\right)_{2} \mathrm{Fe}^{+/ 0} .{ }^{b}$ In DMF/0.1 M Bu $\mathrm{NPF}_{6}(\mathrm{OTTLE}$ cell); absorption maxima in $\mathrm{nm}$, molar extinction coefficients in $\mathrm{M}^{-1} \mathrm{~cm}^{-1}$. ${ }^{c}$ In DMF/0.1 $\mathrm{M} \mathrm{Bu}_{4} \mathrm{NPF}_{6}$ (OTTLE cell); carbonyl vibrational bands $\mathrm{A}_{1}$ and $\mathrm{E}$ in $\mathrm{cm}^{-1}$. ${ }^{d}$ Twoelectron waves. ${ }^{e}$ Not determined due to slow decomposition. 

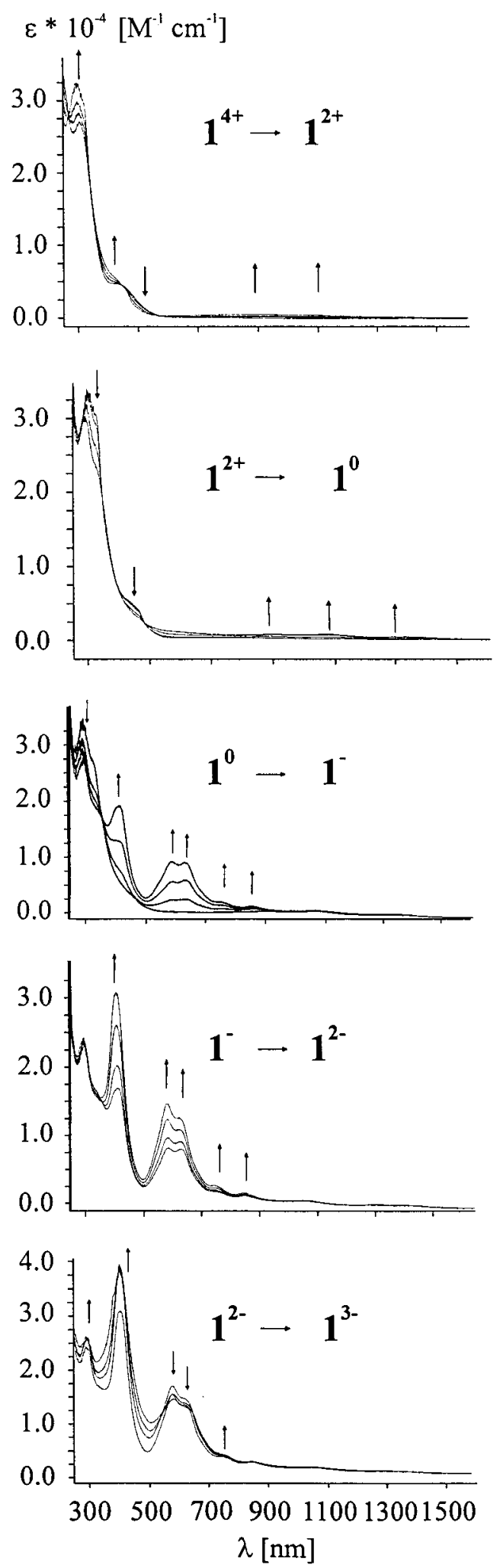

Figure 2. UV/vis Spectroelectrochemistry of $(\mathbf{1})\left(\mathrm{CF}_{3} \mathrm{SO}_{3}\right)_{4}$ in DMF/ $0.1 \mathrm{M} \mathrm{Bu}_{4} \mathrm{NPF}_{6}$. Continuous reduction at the last step causes irreversible degradation.

fourth two-electron waves (Figure 1). This effect is presumably due to increased overall negative charge, which implies electrostatic repulsion. ${ }^{18}$ Other possible factors are conformation changes (twist along the $\mathrm{Re}-\mathrm{N}-\mathrm{-}-\mathrm{N}-\mathrm{Re}$ axes) and the closer proximity of the bp sides (ca. $6 \AA$ ) in rectangular $\mathbf{1}^{4+}$ in comparison to the larger distance of about $11.5 \AA$ between the

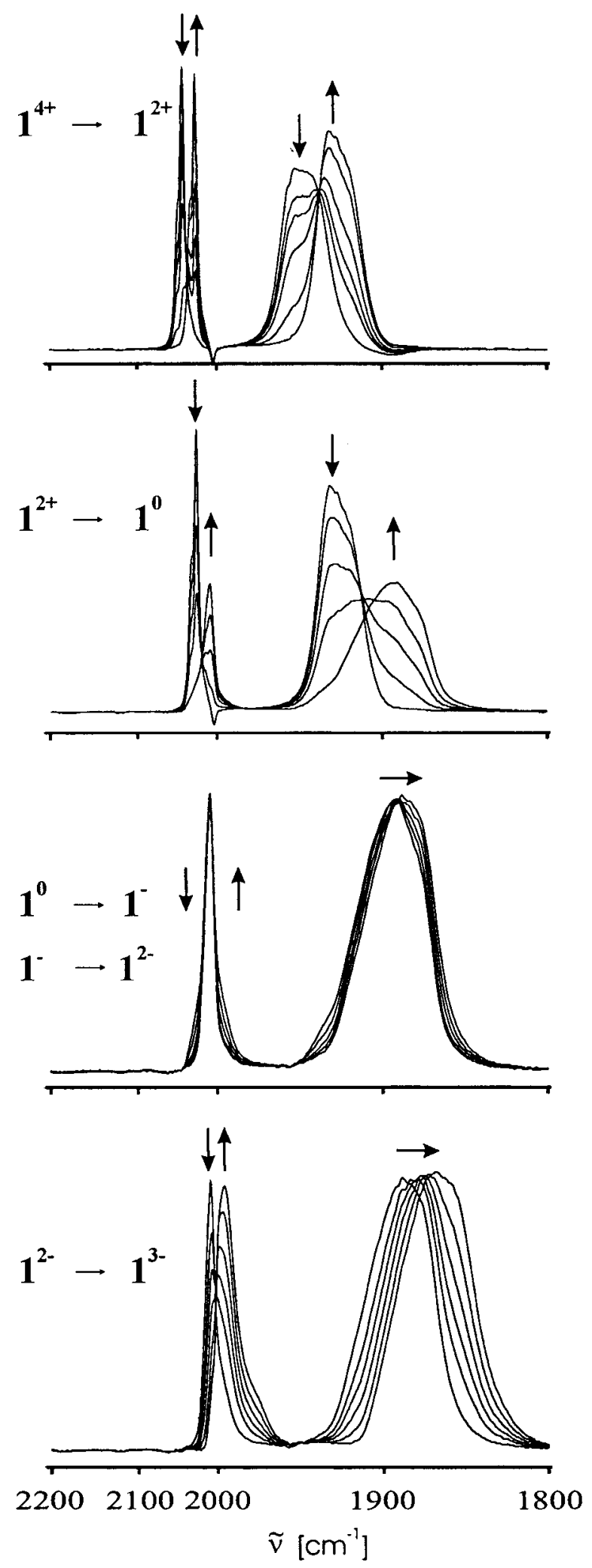

Figure 3. IR spectroelectrochemistry of $(\mathbf{1})\left(\mathrm{CF}_{3} \mathrm{SO}_{3}\right)_{4}$ in $\mathrm{DMF} / 0.1 \mathrm{M}$ $\mathrm{Bu}_{4} \mathrm{NPF}_{6}$. Continuous reduction at the last step causes irreversible degradation.

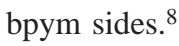

The results presented thus illustrate that $\pi$-conjugated ligand components of molecular rectangle complexes can be charged stepwise with the appropriate number of electrons, adding the "electron reservoir" function to the list of potential uses of such aggregate materials. ${ }^{2-5}$ 


\section{Experimental Section}

Infrared spectra were recorded using a Perkin-Elmer Paragon 1000 FTIR instrument. UV/vis/NIR absorption spectra were recorded on a Bruins Instruments Omega 10 spectrophotometer. Cyclic voltammetry was carried out at $200 \mathrm{mV} / \mathrm{s}$ scan rate in dry ${ }^{9 \mathrm{a}} \mathrm{DMF} / 0.1 \mathrm{M} \mathrm{Bu}_{4} \mathrm{NPF}_{6}$ using a three-electrode configuration (glassy-carbon electrode, $\mathrm{Pt}$ counter electrode, $\mathrm{Ag} / \mathrm{AgCl}$ reference) and a PAR 273 potentiostat and function generator. The ferrocene/ferrocenium couple served as internal reference. Graphical simulation of cyclic voltammograms was performed with a commercially available program ${ }^{12}$ and the data from

(15) Shida, T. Electronic Absorption Spectra of Radical Ions; Elsevier: Amsterdam, 1988; p 198

(16) (a) Braterman, P. S.; Song, J.-I.; Kohlmann, S.; Vogler, C.; Kaim, W. J. Organomet. Chem. 1991, 411, 207. (b) Krejcik, M.; Zalis, S.; Ladwig, M.; Matheis, W.; Kaim, W. J. Chem. Soc., Perkin Trans. 2 1992, 2007.

(17) Stor, G. J.; Hartl, F.; van Outersterp, J. W. M.; Stufkens, D. J. Organometallics 1995, 14, 1115.

(18) Vlcek, A. A., Coord. Chem. Rev. 1982, 43, 39.
Table 1. Spectroelectrochemical measurements were performed using an optically transparent thin-layer electrode (OTTLE) cell. ${ }^{10}$ Reversibility was checked through the appearance of isosbestic points and by obtaining nearly $100 \%$ signal intensity upon reoxidation. The number of electrons transferred in the first step was determined by comparing the diffusion-controlled currents in a large amplitude potential step experiment and the limiting currents from steady-state voltammetry for $(\mathbf{1})\left(\mathrm{CF}_{3} \mathrm{SO}_{3}\right)_{4}$ with those of the ferrocene standard as suggested by Baranski et al. ${ }^{11}$ and finally by controlled-potential electrolysis.

The compound $\left[(\mathrm{bp})_{2}(\mathrm{bpym})_{2}(\mathrm{OC})_{12} \mathrm{Re}_{4}\right]\left(\mathrm{CF}_{3} \mathrm{SO}_{3}\right)\left((\mathbf{1})\left(\mathrm{CF}_{3} \mathrm{SO}_{3}\right)_{4}\right)$ was obtained and characterized as described. ${ }^{8}$

Acknowledgment. This work was supported by grants from the Volkswagen Foundation, Deutsche Forschungsgemeinschaft (DFG), and Fonds der Chemischen Industrie.

Supporting Information Available: Cyclic voltammograms of (1)$\left(\mathrm{CF}_{5} \mathrm{SO}_{3}\right)_{4}$ in $\mathrm{DMF} / 0.1 \mathrm{M} \mathrm{Bu}_{4} \mathrm{NPF}_{6}$ and $\mathrm{CH}_{3} \mathrm{CN} / 0.1 \mathrm{M} \mathrm{Bu}_{4} \mathrm{NPF}_{6}$. This material is available free of charge via the Internet at http://pubs.acs.org.

IC0001006 